\title{
ASSISTÊNCIA À INFÂNCIA: HISTÓRIA DE UMA EDUCAÇÃO MORALIZANTE E HIGIENISTA
}

CHILD CARE: HISTORY OF A MORALIZING AND HYGIENIST EDUCATION

ASITENCIA A LA INFANCIA: HISTORIA DE LA EDUCACIÓN MORALIZANTE Y HIGIENISTA

\author{
GROTTI, Giane Lucélia
}

BEZERRA, Maria Irinilda da Silva²

\begin{abstract}
RESUMO
O objetivo deste artigo é apresentar uma discussão sobre a assistência à infância no Brasil, destacando práticas moralizantes na educação, desenvolvidas com base em preceitos médicos e higienistas. Para tanto, utilizamos como aporte teórico Marcílio (1997, 2006a, 2006b), Rizzini; Marques (2012), Azzi (2008), Sousa (2010), Del Priori (1991), Bazílio (2002), dentre outros. Como resultados, apontamos que a infância no Brasil, por muito tempo foi negligenciada, literalmente abandonada ou colocada à mercê de ações assistencialistas, moralizantes e higienistas. Concluímos que as ações nacionalizantes, típicas da República, visaram criar nas crianças uma vida regrada pelas normas sociais e pelas necessidades do mundo adulto.
\end{abstract}

Palavras-chave: Infância. Assistência. Abandono. Escolarização.

\section{ABSTRACT}

The purpose of this paper is to present a discussion on childcare in Brazil, highlighting moralizing practices in education through medical and hygienist precepts. Our study was based on the following theoretical references: Marcílio (1997, 2006a, 2006b), Rizzini; Marques (2012), Azzi (2008), Sousa (2010), Del Priori (1991), Bazilio (2002), among others. Results show that childhood in Brazil was for a long time neglected, literally abandoned or placed at the mercy of welfarist, moralizing and hygienist actions. We conclude that the nationalizing actions, typical of the Republic, aimed at creating in children an orderly life through social norms and adult world needs.

Keywords: Childhood. Assistance. Abandonment. Schooling.

\section{RESUMEN}

El objetivo de este artículo es presentar una discusión sobre la asistencia para la infancia en Brasil, destacando prácticas moralizantes en la educación, a través de preceptos médicos e higienistas. Para tanto, utilizamos como aporte teórico Marcílio (1997, 2006a, 2006b), Rizzini; Marques (2012), Azzi (2008), Sousa (2010), Del Priori (1991), Bazílio (2002), entre otros. Como resultados, apuntados que la infancia en Brasil, por mucho tiempo fue descuidada, literalmente abandonada o colocada para la merced de acciones asistencialistas, moralizantes e higienistas. Concluimos que las acciones nacionalizantes, típicas de la República, visó crear en los niños una vida regulada por las normas sociales y por las necesidades del mundo adulto.

Palabras clave: Infancia. Asistencia. Abandono. Escolarización.

\footnotetext{
1 Universidade Federal do Acre - UFAC - Rio Branco - Acre - Brasil

2 Universidade Federal do Acre - UFAC - Cruzeiro do Sul - Acre - Brasil
} 


\title{
CONSIDERAÇÕES INICIAIS
}

\begin{abstract}
Um carro em movimento ioca um saco em uma rua de Guarulhos. na Grande São Paulo. Horas denois. outro carro nassa nor cima do saco. Ali havia um recém-nascido. $O$ trácico caso de abandono se soma a belo menos outros 19 no último ano no baís. seaundo levantamento feito nela Folha a nartir de notícias divuldadas nela mídia. "O anonimato imnede o filho de ter suas oriaens reaistradas. neaa o direito à dianidade e à convivência familiar". diz o relator do proieto. debutado Luiz Couto (PT-PB). "Abandono semore existiu e vai existir. Mas permitir o parto anônimo node evitar um abandono tão tráaico. Não é solucão. mas node aiudar". diz o presidente do IBDFAM, Rodrigo da Cunha Pereira (Claudia Colucci - Folha de São Paulo, 11/11/2011, grifos nossos).
\end{abstract}

A epígrafe acima registra mais uma ocorrência flagrada, das tantas invisíveis que há, sobre o repúdio às crianças indesejadas ainda nos dias atuais. Esta prática de jogar, expor em via pública, deixar o recém-nascido à própria sorte, ao longo dos séculos, foi tida como natural, justificada e, por vezes, estimulada com base em vários argumentos que serão explicitados, especialmente, a partir do trabalho de Maria Luiza Marcílio. A opção por trabalhar com base em Marcílio (2006b) deve-se ao fato da autora possuir uma vasta pesquisa empírica de resgate da trajetória do abandono de crianças desde a Antiguidade até o período contemporâneo. Com destaque no Brasil, Marcílio registra as políticas que foram adotadas para a assistência e proteção da infância desamparada com base no que foi realizado em países europeus. Além de apoiar-se nos estudos da referida pesquisadora, este texto foi desenvolvido à luz de outros estudiosos que serviram de referência imperativa para toda e qualquer pesquisa que se conduza ao tema da assistência à infância pobre brasileira.

Tanto o abandono como a proteção e assistência às crianças desvalidas estiveram presentes na sociedade ocidental, se considerarmos as fontes até o momento estudadas. Partir de imediato para uma descrição e estudo dos caminhos da assistência à criança em nosso país demanda necessariamente um entendimento mais abrangente do que se passou em outros países e o quanto esses modelos se fizeram presentes durante a colonização brasileira. A referência que se impôs ao Brasil trouxe modelos vindos de Portugal. Esses padrões, por sua vez, estiveram impregnados de modelos provenientes de outras partes da Europa, especialmente Itália e França.

Tomando como base o exposto acima, este estudo pretende demostrar o quanto o Brasil esteve envolvido em prescrever às populações pobres modelos idealizados de assistência permeados de prescrições médicas de cunho higienista. Para tanto, amparamo-nos em estudos de referência, como os de Del Priori (1991), Bazílio (1998), Marcílio (1997, 2006a), Kuhlmann (2012), dentre outros. A maioria destes estudos indica que esse tipo de assistência, na realidade, possuía o viés moralizador bem explícito, que se revelava em moldar os sujeitos a um único padrão de civilidade, sem considerar, portanto, as especificidades sociais e culturais brasileiras. 


\section{ASSISTÊNCIA ÀS CRIANÇAS NO BRASIL: PERÍODO COLONIAL}

Quando da chegada dos jesuítas ao Brasil, no século XVI, a atenção dispensada às crianças foi gradativamente sendo instituída por meio de um atendimento educacional que visava a submeter a infância indígena aos padrões religiosos católicos. A cultura religiosa europeia foi sendo impressa na criança indígena a partir do ano de 1549 e no decorrer dos dois séculos seguintes (SOUSA, 2010).

Nesse contexto, Del Priore (1991) assinala duas representações de infância que os jesuítas trouxeram em "suas naus", resultando no tipo de tratamento dispensado à criança. A primeira considerava a criança mística, constituindo-se no mito da criança santa, símbolo da pureza e inocência, o que, séculos mais tarde, se configuraria na concepção rousseauniana. Essa concepção mística, rousseauniana, tinha como pano de fundo a beleza e abundância de bens naturais, comida farta que emanava da terra, a terra edênica. A segunda representação - criança que imita Jesus - referia-se à percepção de que a criança seria o espelho de Cristo, símbolo da candura. De acordo com a comparação de Del Priore (1991), em relação ao que Philippe Ariés (1981) interpretou em sua análise, a criança era uma fonte de admiração e distração para o adulto. Esses conceitos estiveram presentes no pensamento, nas orientações e ações dos jesuítas.

No tocante às crianças abandonadas, por um lado Marcílio (2006a, p. 131) destaca que os jesuítas, "[...] nunca criaram uma única instituição destinada à educação da infância desvalida e desamparada. Nunca nenhum pequeno exposto pôde ser admitido nos colégios dos jesuítas". Por outro lado, se tratando especificamente dos órfãos indígenas, Venâncio $(2007$, p. 2) afirma que: "Por volta de 1550, os jesuítas dão início, no Novo Mundo a uma ação pioneira junto às crianças indígenas, criando Colégios de Órfãos para receber curumins sem família". Assim, a afirmativa de Venâncio (2007), de certa forma, contraria o que Marcílio(2006a) destacou sobre o fato dos jesuítas não terem investido em instituições destinadas à educação da infância desvalida e desamparada, e esclarece que criaram, sim, um colégio especificamente para os órfãos indígenas. Pelo que tudo indica, aos olhos dos jesuítas, eram os nativos da terra que mais careciam de amparo.

Couto \& Melo (1998) salientam que, posteriormente, quando da vinda dos escravos africanos ao Brasil, as crianças mestiças (filhas de brancos ou negros com mulheres índias) eram comumente abandonadas e recolhidas em lugares denominados de "Casas de Muchachos" com a finalidade de educá-las dentro dos preceitos da religião católica. Este dado denota que os jesuítas acolheram não somente os órfãos, mas os enjeitados e os ilegítimos, se considerarmos que a missão católica esteve sob responsabilidade deles naquele período histórico. No ano de 1585 já existiam cinco dessas chamadas "casas de acolhimento", situadas em Ilhéus, Porto Seguro, Espírito Santo, São Vicente e São Paulo (COUTO; MELO, 1998, p. 21).

As casas de acolhimento, na realidade, eram importantes instrumentos de conversão dos jovens indígenas à fé católica, uma vez que residindo naquele espaço, assimilavam mais facilmente os valores e dogmas católicos através da convivência cotidiana com os religiosos. Riolando Azzi, ao comentar sobre a catequese infantil, no início da formação da sociedade brasileira, ressalta que os 
jesuítas fizeram uma opção declarada pelos mais jovens, percebendo que "os meninos eram mais fáceis de serem convertidos e catequizados, sendo mais maleáveis e amoldando-se com mais rapidez à cultura lusitana" (2008, p. 22). Partindo desse objetivo, foram, inclusive, trazidos de Portugal alguns órfãos para que convivessem com as crianças e jovens indígenas, de modo a facilitar a assimilação dos valores lusitanos e cristãos. Ações dessa natureza permaneceram presentes em todos os períodos da história brasileira nos quais as crianças e adolescentes órfãos foram vistos como um perigo para a sociedade nacional e, como tal, tornaram-se objetos das mais diversas ações, que foram do abandono até às diferentes formas de assistência social.

Com base nesses registros, afirmamos que $\mathrm{O}$ atendimento às crianças, abandonadas, indesejadas ou órfãs teve seu início, no Brasil, ainda no período colonial, por meio da ação da Igreja católica, mais especificamente da ordem dos jesuítas, sustentado pelo viés religioso colonizador de dominação.

\section{ATENDIMENTO CARITATIVO}

Durante o período Colonial, a assistência às crianças abandonadas fora realizada pela Igreja e pelo Estado. Tanto um quanto outro tão somente cumpriram determinadas formalidades legais e jurídicas. O que havia, na realidade, era uma movimentação da sociedade civil em torno de prestar algum auxílio no sentido caritativo. Essa acepção caritativa foi a primeira forma de atendimento prestado às crianças expostas. A partir dessa constatação, Marcílio (2006a) apresenta três formas distintas de atendimento: a primeira refere-se às políticas de atendimento por vias oficiais através das Câmaras Municipais. Por determinação de D. Manuel, em 1521, coube a estas cuidar de assistir as crianças abandonadas. A segunda é a adoção do sistema de acolhimento através da Roda dos Expostos $^{3}$, medida que implicou em resguardar a criança de ser abandonada em lugar público. A terceira característica de atendimento daquele período foi a benevolência intencional de famílias que acolhiam as crianças em suas casas, por vezes, com o intuito de torná-las servas e até mesmo escravas. Marcílio (2006a) destaca que essas duas últimas formas de atendimento caminharam juntas no decorrer do período imperial até as décadas finais do século $\mathrm{XX}$, com a instalação do Estado de Bem-Estar Social. Finalmente, a assistência social à criança desfavorecida socialmente é assumida pelo poder público. A partir de então, criam-se leis para assegurar-lhes o lugar de cidadã.

Em outra análise, Bazílio (1998) também ressalta que, ao longo do tempo, no Brasil, três fases da assistência foram identificadas. A primeira fase abrange desde a colonização até por volta da segunda década do século $X X$, período em que foi oferecido às crianças pobres abandonadas o atendimento filantrópico ou assistencial, (cognominadas em diferentes momentos históricos como enjeitadas, expostas, desvalidas, carentes, capoeiras, e outras definições). A segunda fase, de 1920 a

\footnotetext{
3 Esse instrumento tratava-se de um cilindro giratório na parede, normalmente instalado em hospitais e de instituições religiosas que recebiam crianças "bastardas" ou com deformidades físicas, ou doentes mentais, sem que a pessoa que a colocasse naquele dispositivo fosse identificada. Para maior aprofundamento ver: MARCÍLIO, M. L. (2006a). A Roda dos Expostos e a Criança Abandonada no Brasil Colonial: 1726-1950. In: FREITAS, M. (org.). História Social da Infância no Brasil. São Paulo: Cortez, 2006.
} 
1980, compreende o período em que o Estado brasileiro criou "um corpo jurídico/institucional" para atendimento à infância. E finalmente, a terceira fase compreende as duas últimas décadas do século XX a qual foi marcada pela: [...] entrada em cena das Organizações Não Governamentais - ONGs; pelo desmonte que o estado brasileiro efetuou em suas instituições de atendimento; pela participação da sociedade civil na elaboração do Estatuto da Criança e do Adolescente (BAZÍLIO, 1998, p.49).

Diante do exposto, para os autores/ras anteriormente citados/as, há uma cronologia similar nas formas de atender à infância carente ao longo da história. Marcílio (2006a) deixa clara uma ordem quanto ao atendimento, partindo do caritativo, depois filantrópico e, por fim, o assistencial. Bazílio (2002) explicita a compreensão na mesma direção, de que houve no Brasil os atendimentos caritativo, filantrópico e assistencialista. Não há uma superação entre eles o que aconteceu foi uma coexistência entre os três.

A respeito do atendimento de cunho caritativo, podemos destacar que essa base data da Idade Média, em que a assistência caritativa distinguia o pobre como um eleito de Deus, a quem a Igreja e seus clérigos incentivavam o exercício da caridade. Ajudar o pobre seria um dever para o rico, um modo de se redimir da vida abastada, cheia de regalias para a alma e, quanto aos pobres, seria uma benção recebida da parte de Deus, pois "as grandes religiões [...] atribuem à pobreza um estatuto santificante; a riqueza, pelo contrário, não é um valor dignificado nos primeiros modelos sócio culturais" (GEREMEK, 1986, p.13). Segundo Geremek (1986), as pessoas mais abastadas da sociedade tinham essa prática como um meio de aplacar sua consciência, pois através de boas ações, conforme a doutrina cristã, receberiam o apagamento de seus dolos e, dessa maneira, poderiam ter passagem livre ao empíreo, além de cultivar uma boa imagem perante a sociedade, que passava a reconhecê-los como homens e mulheres benevolentes, merecedores de destaques e privilégios.

O indivíduo que recebia ajuda deveria sentir-se grato a Deus por seu estado de humildade, devendo ser esta a principal característica da vida de um cristão, ser capaz de demonstrar gratidão à uma ajuda não merecida. Era interessante manter o pobre em seu nível de penúria, pois o sujeitando e o conformando a sua condição de desigual em relação à pessoa que the socorresse, favorecia a manutenção do status social. Nesse contexto, a Igreja era o meio pelo qual essa criatura que se encontrava desprovida de elementos de subsistência poderia obter algum avanço em seu nível social e ainda Ihe era concedida a salvação espiritual (KUHLMANN, 2012). A pobreza, vista como uma benção recebida dos céus, deveria ser suportada piedosamente como um flagelo necessário, como o de Cristo, de carregar na carne as aflições da pobreza para a santificação da alma. Aquele que nascido rico tinha por obrigação manter-se fiel aos princípios da caridade.

Em se tratando de abrigar crianças enjeitadas e expostas, tais conceitos cristãos estiveram presentes no Brasil desde o início da colonização, e perdurou até meados do século XIX. Basicamente, essa atividade destinava-se às crianças pobres e aos desvalidos, que, através de esmolas, recebiam paliativos para minimizar sua condição de miséria. Assim, desde a Colonização até o Império, instituições religiosas e pessoas ligadas à Igreja acolhiam as crianças abandonadas. À 
frente desse acolhimento, a Igreja adotou, no Brasil, a "Roda dos Expostos" similar às que foram criadas em países europeus.

A Roda dos Expostos foi um sistema inaugurado ainda na Europa medieval como uma maneira de se evitar o abandono de bebês pelas ruas, florestas, rios e nas portas das casas e de igrejas. Além disso, impedia a exposição social dos abandonadores, como é possível verificar a seguir:

Fundada para proteger a honra da família colonial e a vida da infância, a Casa dos Expostos terminou por obter um efeito oposto ao inicialmente previsto. Dispondo da roda, homens e mulheres passaram a contar com um apoio seguro para suas transgressões sexuais. Estavam certos de que podiam esconder os filhos ilegítimos em local onde seriam bem tratados. De protetora da honra, a Casa tornou-se incentivo à libertinagem (COSTA, 2004 p. 164-165).

Costa (2004) destaca que a Roda dos Expostos foi idealizada para conter a prática de infanticídio, muito comum à época. Entretanto, em certa medida, serviu também para acobertar o fruto de relações sexuais consideradas ilícitas, agregando-se aos objetivos assistencialista e caritativo, uma vez que acolhiam as crianças indesejadas que costumeiramente eram abandonadas em locais ermos e insalubres. Nestes locais, consequentemente, acabavam morrendo vitimadas por circunstâncias diversas: como exposições a animais e a condições climáticas desfavoráveis.

Pautado em conceitos morais e religiosos, a Roda dos Expostos cumpriu até certo ponto seu intento, visto que "convertera-se pela pobreza de instalações e meios de manutenção, num verdadeiro autóctone de mortalidade infantil" (COSTA, 2004, p. 165). Este mesmo autor ressalta que a Roda foi muito utilizada pelas mães escravas no intuito de resguardar a criança do trabalho servil, e para os seus senhorios, era mais uma forma de renda ao colocar suas escravas como amas de leite.

Como mencionamos acima, a prática de abandono nas Rodas e em instituições similares foi comum em muitos países europeus e foi praticada por milhares de pessoas que não se sentiam obrigadas a acolher e proteger seus filhos ou parentes. Como exemplo, podemos citar o caso de Rousseau, um dos maiores pensadores e teóricos do campo da infância do século XVIII, que abandonou seus cinco filhos na Roda dos Enjeitados. Como o pedagogo que "inventou a infância" foi capaz de abandonar seus filhos nessas circunstâncias?

Para pensar nessa questão, precisamos nos reportar à sociedade de Rousseau. Como afirma Danilo Strek (2004, p. 18), essa prática "era comum na época, tanto para aqueles que não tinham condições de criar os seus filhos quanto para aqueles que por uma ou outra razão não os desejavam". E embora Rousseau demonstre em algumas situações seu desconforto com essa decisão, pontua que "[...] foi a melhor saída e que, nas mesmas circunstâncias, voltaria a fazer o mesmo" (STREK, 2004, p.19). Assim sendo, não havia um princípio moral, socialmente construído que contrariasse tais atitudes de abandono aos menores. Ficava simplesmente a critério dos pais ou responsáveis a opção por assumir a tarefa de educá-los ou simplesmente abandoná-los à própria sorte nas instituições criadas como depósito desses enjeitados. 
No caso do Brasil, as Câmaras Municipais estiveram encarregadas de prover a preservação da vida dos bebês até a abertura das primeiras Rodas. Esses dois sistemas de acolhimento recorriam às amas de leite ou às mães mercenárias ${ }^{4}$ para cuidar e alimentar os enjeitados. Infelizmente, ambas as formas não deram conta de atender o número elevado de crianças abandonadas. As justificativas para o não acolhimento total dos enjeitados deveu-se à falta de recursos para o pagamento das amas, mesmo sendo um valor em dinheiro muito baixo. Outro motivo foi a escassez de Rodas instaladas nas cidades.

As Rodas estiveram sempre ligadas às Santas Casas de Misericórdia, uma vez a criança sendo colocada naquele instrumento tomava o seguinte caminho:

Logo que o bebê entrava na instituição, a primeira preocupação dos responsáveis era com seu batismo. [...] uma vez batizado, buscava-se encontrar o mais rapidamente possível a casa de uma ama de leite para enviar o bebê. [...] com as amas, ficava o pequeno exposto, em princípio, durante os seus três primeiros anos de vida. A partir dessa idade seu destino era incerto (MARCÍLIO, 1997, p. 151).

Havia uma porcentagem de crianças que, após anos de convívio com as amas, retornavam às Rodas, pois essas mulheres não possuíam condições financeiras para continuarem a cuidar dessas crianças. Por conseguinte, tornavam-se enjeitadas pela segunda vez. As que não retornavam às Rodas eram encaminhadas a realizar trabalhos forçados, outras iam para as ruas mendigar, servir à prostituição e, até mesmo, realizar pequenos furtos para sobreviver.

Interessante ressaltar que as amas de leite eram mulheres extremamente pobres, em sua maioria escravas, ou ex-escravas, algumas moravam sozinhas ou, às vezes, eram concubinas, mães solteiras, ou mulheres que se disponibilizaram a criar os filhos dos outros por um pouco de dinheiro. Quando se encerravam os 3 anos, o percentual pago diminuía, o que era um contrassenso, pois quanto maior a criança, maiores suas necessidades de subsistência.

\section{CRIANÇA, O FUTURO DA NAÇÃO}

Rizzini; Marques (2012), em estudo sobre a distribuição e circulação das infâncias na capital federal durante as décadas de 1900 e 1910, ressaltam que as crianças não escolarizadas, em geral órfãs e abandonadas, eram intituladas de "os incorrigíveis da cidade", recebendo nomes pejorativos como vadias e vagabundas. Por meio da análise de relatórios e comunicados enviados pelos diretores das instituições de acolhimentos às autoridades da cidade, os autores destacam a forma como essas crianças eram tratadas, ou melhor, destratadas.

\footnotetext{
${ }^{4}$ Mães mercenárias eram mulheres que se prontificavam a cuidar de crianças, (enjeitadas, órfãs ou abandonadas) especialmente as bem pequenas, por algum dinheiro, comida ou favores. Em geral, as crianças eram pouco nutridas por essas mães e acabavam adoecendo e vindo a falecer, devido, também, à falta de cuidados básicos e de condições salubres. Com isso, foram também denominadas de mães fazedoras de anjos.
} 
Os asylados eram vistos como crianças sem amor pelo estudo e com comportamentos incorrigíveis. Dessa forma, já tendo vivido a triste experiência de terem sido abandonadas pelos familiares, eram comumente transferidos para várias instituições, pois não se adaptavam às fortes normas de condutas impostas à sua infância. Além disso, eram objeto de "uma poderosa engrenagem, pautada nos mais diversos conhecimentos científicos (higienista, filan bn trópico, jurídico e educacional)" que recaiam sobre os "desfavorecidos e alguns "indesejados" da capital federal" (RIZZINI; MARQUES, 2012, p. 16, grifos dos autores). Para esse público, era pensado um tipo específico de educação/escolarização oferecida em instituições, que se diferiam dos espaços de formação organizados para as demais parcelas da sociedade. Sendo,

[...] uma parcela da população infantil, composta em sua maioria por meninos identificados como órfãos ou menores abandonados, alvo de um tipo específico de escolarização empreendida pelo poder público [....] População essa presente, tanto na documentação administrativa quanto na produção literária, como uma ameaça à ordem social (RIZZINI; MARQUES, 2012, p 17).

Como podemos observar, as crianças identificadas como abandonadas acabavam sendo compreendidas pelas autoridades do Estado como uma ameaça à ordem social. E, para se reverter essa situação, era necessário oferecer a essas crianças uma educação pautada pelos princípios higienistas, uma educação moral e cívica que preparasse para o mundo do trabalho. Afinal, nesse período, o trabalho, era uma forma de dignificar e civilizar a população pobre. Voltados à formação para o trabalho, os internatos para órfãos e abandonados "se constituíram como elementos cruciais no combate a desordem social, concomitante a ação policial" (RIZZINI; MARQUES, 2012, p. 17). Essas instituições de educação nos ofícios eram mais conhecidas como internatos profissionais.

A partir do final do século $\mathrm{XIX}$, as ações voltadas para as crianças órfãs e abandonadas assumiram um caráter social e político, de forma que esses denominados menores tornaram-se alvo da intervenção formadora/reformadora do Estado em parceria com outras instituições religiosas ou filantrópicas. Essas ações tiveram como finalidade conter o avanço do caos social que se instalava no país. Às crianças e jovens abandonados eram atribuídos adjetivos como "vagabundos" e "criminosos".

A desordem social, denunciada por políticos, intelectuais, filantropos e outros, no decorrer da primeira República, foi exposta como um dos principais problemas que o país vivia e sua solução estava, necessariamente, na organização de instituições de educação e escolarização, que, atuando na assistência e moralização desses menores desvalidos, organizariam o país aos moldes de uma nação civilizada. Assim sendo, podemos afirmar que os anos iniciais da República foram determinantes na definição da atuação do poder público em relação ao atendimento dessas crianças denominadas de desvalidas. E com essa finalidade, um conjunto de leis foi sendo publicado: O Código Penal (1890), a Legislação sobre o trabalho infantil (1891) e a Assistência a Infância Desvalida (1890). Mas quem eram essas crianças atendidas por esses estabelecimentos mantidos pelo poder público? No caso específico da capital, a legislação traçava o perfil dessas crianças e o local no qual deveriam ser acolhidas, conforme a idade. 
[...] os abandonados em via pública, não sendo reclamados pelos pais, tutores ou protetores em condições de prover sua manutenção; os órfãos de pai e mãe, quando a indigência seja provada; os órfãos de pai, sob a mesma condição; os que tendo pai e mãe, não puderem ser por estes mantidos e educados física ou moralmente, dando-se amparo forçado; os que apresentassem algumas ou todas essas condições. Nesses casos, seriam admitidos, conforme a idade, ou na Casa de São José (6-12 anos) ou no Asilo de Meninos Desvalidos (12-14 anos) (RIZZINI; MARQUES, 2012, p. 24).

Observamos que na República a legislação brasileira voltada para a assistência aos abandonados, tais como o Código Penal, a Legislação sobre o trabalho infantil e a Assistência a Infância Desvalida continuava tendo como pano de fundo a necessidade de livrar as cidades do incômodo causado por esses sujeitos expostos nas ruas das principais capitais do país. $E$, nesse contexto, nada melhor do que instituições que acolhessem, civilizassem e preparassem para o mundo do trabalho produtivo. Essa necessidade não somente continua, como se intensifica no período do pósguerra, quando a comunidade internacional passa a ver a educação como uma questão de necessidade social, visto que atuaria na transmissão de valores morais e humanos, no preparo do espírito pacífico, capaz de evitar uma nova guerra.

Nessa direção, Wadsworth (1999, p. 2) aponta que o fim da Primeira Guerra Mundial trouxe a preocupação em preparar "as futuras gerações de brasileiros para o progresso nacional". O tão almejado progresso se daria através de muito trabalho produzido por uma sociedade física e moralmente sadia. Diversas áreas da atividade humana foram influenciadas pelas ideias de avanço e modernização, que incluíam a concepção de trabalho como "novo arquétipo de valores que a sociedade deveria aspirar", sendo um instrumento para conter a desocupação e a "vagabundagem", portanto, o elemento chave para conquistar o status de sociedade moderna e civilizada (ARAUJO, 2011, p. 171).

Para Rizzini (2011, p. 103), no século XIX "a ideologia do trabalho fez com que a condição de trabalhador funcionasse como um atestado de virtude, [...] constituindo instrumento poderoso de regulação econômica e social" e, em relação à criança, o nexo era adaptá-la o quanto antes ao trabalho, mantendo-a ocupada com sua subsistência e garantindo mais um braço para o capital.

Os grandes centros urbanos abrigavam um amplo contingente de pessoas sem trabalho, sem moradia, e sem assistência médica. A taxa de mortalidade infantil era alta, incorporados a esses problemas, a preocupação com as condições sanitárias estava evidente, o que levou as autoridades a entenderem que o espaço urbano deveria ser sanado dessas moléstias. Portanto, a classe médica foi elevada ao patamar de responsável pelas condições de salubridade das pessoas. Os principais fatores que cooperaram para formação desse quadro foram o fim do período de escravismo, a migração de colonos do campo para as cidades devido ao declínio do café, a partir de 1920, culminando na crise de 1929. Atreladas à necessidade urgente de mão de obra para o trabalho nas indústrias, as cidades incharam-se da noite para o dia, sem as devidas medidas básicas estruturais para atender a demanda.

A pobreza que sempre existiu tornou-se explícita nas ruas das "cidades que se industrializavam e transformavam famílias inteiras em trabalhadores ativos ou na reserva, de todo o modo, pobres" (RIZZINI, 2011, p.102). Famílias inteiras significam a presença de crianças e, nesse 
contexto de urbanização crescente, as questões relacionadas a elas passaram a ser o alvo da atenção dos médicos, filantropos, pedagogos, políticos, moralistas e juristas que, em seus discursos, incorporavam medidas e ações evidenciando-as como origem e o futuro da nação, portanto, deveriam ser bem assistidas e protegidas. Subjacente a essa concepção de cuidados assistencialistas, Levy, (1996, p. 11) destaca que "a criança representa um capital para a família e para o país", cuidar bem dela seria um investimento seguro.

O ideário de um país nascente nos moldes republicanos o identificava como um país criança, em que tudo ainda estava para acontecer. Além disso, pautava-se nos preceitos eugênicos, que se seguidos, culminariam em uma população forte e saudável. Esses princípios deveriam ser adotados, a fim de livrar o país das degenerescências, identificadas nas classes pobres, e que comprometiam o plano de construção de uma nação potente. Convencidos da relevância desses princípios e cientificamente embasados, um amplo processo se iniciou a despeito do saneamento moral dos pobres, das prostitutas, das crianças e demais grupos que, segundo a visão dos médicos, juristas, pedagogos, precisariam de tutela para eliminar qualquer vestígio de personalidade ou conduta que não estivesse em consonância com os das classes média e alta da sociedade.

Assim, nos primeiros anos do século $X X$, instituições públicas e privadas, com subvenção governamental, atendiam a infância necessitada, sem qualquer controle centralizado e não desenvolvia um programa com bases científicas e jurídicas que oferecesse sustentação à população carente. Sobre esta questão encontramos contribuição em Rizzini (2009) quando a autora afirma que o estabelecimento de políticas de assistência à infância naquele momento "era privilégio de uma elite formada por autoridades, intelectuais, pessoas da boa sociedade" (p. 280).

A elite formulou outro entendimento de infância, diferente daquela imagem da infância símbolo de pureza e inocência, livre dos pecados. Esta infância agora estava pautada numa concepção científico-racional do mundo. Para a criança pobre, restaria ser atendida em suas necessidades mediante as concepções capitalistas. Esta concepção objetiva "moldá-la para submissão" (RIZINNI, 2011, p. 29). Ainda de acordo com a autora, o país investiu numa política jurídico-assistencial de atendimento à infância, ao invés de oferecer educação de qualidade. Nesse período, uma educação de qualidade, e de acesso a todos era contrária à formação de uma massa populacional, que precisava ser mantida submissa, a fim de garantir a demanda da industrialização pela qual o país passava.

Crianças provenientes das camadas sociais mais pobres da sociedade, quando abandonadas, eram por vezes tratadas como menores e ainda identificadas com outros adjeitovos tais como: desamparadas, delinquentes ou vagabundas. E diante da pressão social por limpar o país das más condições que o identificava como país atrasado e incivilizado, do ponto de vista jurídico, foram criados mais outros mecanismos para recolhê-las em: "Colônias Agrícolas, Asilos, Casas de Correção, Educandários, Reformatórios" (ABREU; MARTINEZ, 1997, p. 22 - 24). Nesse contexto, foi instituído o Código de Menores em 1927, de forma a sistematizar o tratamento designado aos menores taxados de delinquentes. Esse código tornou-se um marco na história da assistência e proteção à infância no 
Brasil, pois materializa, a favor do menor, as leis de assistência e proteção. Coaduna com a visão jurídica sobre a infância uma outra, sobre a qual Marcílio assinala:

Com o século XIX chega a influência da filosofia das luzes, do utilitarismo, da medicina higienista, das novas formas de se exercer a filantropia e do liberalismo, diminuindo drasticamente as formas antigas de caridade e solidariedade para com os pobres e desvalidos (MARCíLIO, 2006a, p.67, grifos nossos).

Em conformidade com o que ressaltou Marcílio (2006a), Abreu; Martinez (1997) acrescentam que, no final do século XIX, a partir do estabelecimento do Ensino Superior no Brasil, a temática sobre a criança e sobre a concepção de infância surgiu com maior vigor dentro da área da medicina voltada para o higienismo. Os debates médicos versavam sobre a educação das crianças pobres e das mães, dando destaque sobre: os esclarecimentos quanto a importância da amamentação, os riscos de se adotar amas de leite sem uma avaliação criteriosa de suas condições físicas, higiênicas, morais, e outros temas relativos à saúde, educação, infanticídio, doenças, mortalidade infantil, nutrição, sanidade pessoal e do ambiente.

Nessa direção, Rizzini (2011) destaca que a proposta de civilizar o país passou pelas mãos dos médicos, designando a necessidade de sanar, curar os males que as classes pobres apresentavam, particularmente, os males de cunho moral, vistos como desvio do padrão, em relação às classes média e alta. Assim sendo, o desenvolvimento da medicina social, atrelada às novas descobertas neste campo, promoveu a difusão da noção de higiene, impondo-a como condição para o desenvolvimento. A criança passou a ser vista como essencial à construção de uma nação sadia,

[...] principalmente porque já se pesava na utilidade deste sujeito à nação, na forma de mão-deobra para a indústria (...) para a formação de um Estado nacional, forte unido em torno dos ideais da pátria, com uma população dócil, ciente de seus deveres e de seu lugar (RIZZINI, 2009, p. 280).

Sartor (2000, p. 145) registra que a assistência à infância no Brasil, sempre reproduziu "mecanismos de controle social, perpetuando a segregação entre as classes". A autora enfatiza que o problema da infância ${ }^{5}$ pobre nunca foi enfrentado com propostas consistentes, estas apenas estiveram voltadas a promover o crescimento do sistema capitalista. Conforme apontam Vieira (1986), Rizzini (2011) e Grotti (2016):

[...] a dimensão social da infância dentro desse contexto, esclarecendo que o interesse pela infância no final do XIX refletia as novas ideias de emancipação e construção de uma identidade nacional ${ }^{6}$. A criança foi vista com potencial para se tornar um bom homem "civilizado" ou um degenerado "incivilizado", portanto, deveria receber atendimento adequado, evitando-se qualquer possibilidade de desvio da construção de uma nação civilizada, tendo por modelo de civilidade o ideário europeu ${ }^{7}$. Sendo assim, ela deveria receber cuidados, atenção e assistência, a fim de

\footnotetext{
${ }^{5}$ Conferir em: (GROTTI, 2016, p. 15).

${ }^{6}$ Segundo o registro em Alunos Rústicos, Arcaicos e Primitivos: o pensamento social no campo da educação. Nesse texto, Marcos Cezar Freitas faz a análise da identidade nacional como o "tempo da homogeneidade a ser construída". (FREITAS, 2005, p.47).

${ }^{7}$ Essa discussão encontra-se na parte introdutória da obra: O Século Perdido, de Irene Rizzini, sob o título: Na criança está o futuro da Nação: a dimensão social da infância (RIZZINI, 2011).
} 
Autores como Herschann; Pereira (1994) e Naxara (1998) afirmam que essa intenção em alcançar a tão almejada civilidade, prescindia de transformar os indivíduos em cidadãos conforme o modelo estrangeiro vigente. Tal modelo seguia o padrão de nações europeias cujas características étnicas, culturais, raciais eram buscadas de forma a eliminar a mestiçagem brasileira, e o atraso que se dizia ter o Brasil em relação ao desenvolvimento técnico e científico daquelas nações.

O padrão estabelecido apontava a criança e o jovem como o futuro da nação que se almeja conquistar, portanto, a eliminação de traços indesejados como a pobreza, as moléstias, os desvios de conduta, e os vícios foram combatidos com ações médicas e de cunho policial, a fim de produzir uma nova imagem do país (SARTOR, 1997; CAMARA, 2010, 2011; KUHLMANN, 2012).

\section{CONSIDERAÇÕES FINAIS}

Confirmamos, por meio da bibliografia consultada, que em vários contextos e períodos históricos as crianças não foram ouvidas em suas necessidades, vontades e opiniões. Essa atitude em relação a elas também foi construída historicamente, cujas representações encontraram seu fundamento na Idade Média quando a criança pobre era compreendida como uma escolhida por Deus para que as classes favorecidas pudessem treinar sua caridade. Assim, recebiam uma assistência de cunho caritativo, incentivada pela Igreja Católica que propagava o sentimento de caridade àqueles despossuídos de condições financeiras.

No Brasil, a partir de modelos estabelecidos como ideais, desde o início de sua colonização, adotou um atendimento às crianças indígenas, órfãs, abandonadas e enjeitadas, sob o viés moralizador. As ações empreendidas em termos de assistência buscavam um padrão de comportamento com base em orientações e prescrições médicas pautadas no higienismo. O padrão instituído era o das nações europeias símbolo de civilidade e modernidade.

Evidenciamos que as formas de atendimento às crianças, embora com objetivos e finalidades diversas, sejam de cunho caritativo, filantrópico, assistencial e/ou educacional, estiveram presentes durante a constituição histórica do povo brasileiro. Mas, enfim, houve atendimento, demonstrando como elas estavam em evidência na sociedade, ora sendo compreendidas como estorvo, ora sendo tratadas como o futuro de uma nova nação que se queira construir sob a ótica de civilidade e de modernidade e, nessa direção, deveriam ser bem tratadas e educadas.

A História nos aponta os caminhos percorridos e a percorrer e em relação ao atendimento às crianças pobres, ainda temos um longo caminho a trilhar para que possamos ser considerados uma nação que oferece as suas crianças e adolescentes um atendimento que acolhe a todas as necessidades emocionais, físicas, cognitivas e psicológicas destes sujeitos. 


\section{REFERÊNCIAS}

1. ABREU, Martha; MARTINEZ, Alessandra Frota. Olhares sobre a criança no Brasil -perspectivas históricas. In: RIZZINI, I. (org.) Olhares sobre a criança no Brasil: séculos XIX e XX. Rio de Janeiro. Petrobrás-BR/ Ministério da Cultura / EDUSU / Amais. Livraria e Editora: 1997, p.19-37.

2. ARAUJO, Vania Carvalho de. A Criança socialmente Desvalida: entre o trabalho e a ameaça da Lei. In: FARIA FILHO, Luciano Mendes; ARAUJO, Vania Carvalho de História da Educação e da Assistência a Infância no Brasil (orgs.). Vitória EDUFES, 2011, p. 171-205.

3. ARIÈS, Philippe. História Social da Infância e da Família. 2a . ed. Rio de Janeiro: Guanabara, 1981.

4. AZZI, Riolando. A Igreja Católica na Formação da Sociedade Brasileira. Aparecida, SP: Santuário, 2008.

5. BAZÍLIO, Luiz Cavaliere; EARP, Maria de Lourdes Sá; NORONHA, Patricia Anido. Infância tutelada e educação: história, política e legislação. Rio de Janeiro: Ravil, 1998.

6. CAMARA, Sonia. Sob a Guarda da República: a infância menorizada no Rio de Janeiro na década de 1920. Rio de Janeiro: Quartet, 2010.

7. Infância Pobre e Instituições Assistenciais no Brasil Republicano. In: FARIA FILHO, Luciano Mendes; ARAÚJO, Vania Carvalho (orgs.). História da Educação e da Assistência à Infância no Brasil. Vitória: EDUFES, 2011, p. 17-56.

8. COSTA, Jurandir Freire. Ordem Médica e Norma Familiar. Rio de Janeiro: Edições Graal, 2004.

9. COUTO, Inalda Alice Pimentel; MELO, Valéria Galo. Reconstruindo a história do atendimento à infância no Brasil. In: BAZÍLIO, Luiz Cavaliere; EARP, Maria de Lourdes Sá; NORONHA, Patricia Anido. Infância tutelada e educação: história, política e legislação. Rio de Janeiro: Ravil, 1998. p. 20-38. 
DEL PRIORE, Mary. Apresentação. In: Histórias das Crianças no Brasil. São Paulo: Contexto, 1991.

11. FREITAS, Marcos Cezar. Alunos Rústicos, Arcaicos e Primitivos: o pensamento social no campo da educação. São Paulo: Cortez, 2005.

GEREMEK, Bronislaw. A piedade e a forca: história da miséria e da caridade na Europa. Lisboa: Terramar, 1987.

GROTTI, Giane Lucélia. História da Assistência à Criança Pobre em Rio Branco - Acre: instituições, sujeitos e ações na década de 1940. Tese de Doutorado em Educação. Programa de Pós-Graduação em Educação- UFPR. Curitiba 2016.

14. HERSCHMANN, Micael M. e PEREIRA, Carlos Alberto M. O Imaginário Moderno no Brasil. In: A invenção do Brasil Moderno: medicina, educação e engenharia nos anos 20-30. HERSCHMANN, Micael M. e PEREIRA, Carlos Alberto M.(orgs.). Rio de Janeiro: Editora Rocco, 1994, p. 9-42.

KUHLMANN JR, Moysés. Ideias sobre a Educação da Infância no $1^{\circ}$. Congresso Brasileiro de Proteção à Infância, Rio de Janeiro, 1922. Disponível em:< http://www.sbhe.org.br/novo/congressos/cbhe2/pdfs/Tema7/0749.pdf>. Acesso em 14/11/2012.

LEVY, lete Cherem. A trajetória de Moncorvo Filho: puericultura e filantropia num projeto de assistência a infância. Dissertação. (Mestrado em História) Programa de Pós-Graduação em História do Brasil. Universidade Federal do Rio de Janeiro - Rio de Janeiro, 1996. mimeo.

17. MARCÍLIO, Maria Luiza. Amas de Leite Mercenárias e Crianças Expostas no Brasil. In: Olhares sobre a Criança no Brasil. RIZINNI, Irene (org.). Rio de Janeiro: Petrobrás BR: ministério da Cultura: USU Ed. Universitária, 1997. A Roda dos Expostos e a Criança Abandonada no Brasil Colonial: 1726-1950. In: FREITAS, M. (org.). História Social da Infância no Brasil. São Paulo: Cortez, 2006a. p.53-79. História social da criança abandonada. 2. ed. São Paulo: Hucitec, 2006b. 
NAXARA, Márcia Regina Capelari. Estrangeiro em sua Própria Terra: representações do brasileiro 1870/1920. São Paulo: Annablume, 1998.

21. RIZZINI, Irma. Meninos desvalidos e menores transviados: a trajetória da assistência pública até a Era Vargas. In: RIZZINI, Irene; PILOTTI, Francisco (orgs.). A Arte de Governar Crianças. São Paulo: Cortez, 2009.

RIZZINI, Irene. O Século Perdido: raízes históricas das políticas públicas para a infância no Brasil. São Paulo: Cortez, 2011.

RIZZINI, Irma; MARQUES, Jucinato. Os incorrigíveis da cidade: um estudo sobre a distribuição e circulação das infâncias na capital federal durante as décadas de 1900 e 1910. In: LOPES, Sonia de Castro; CHAVES, Miriam Waidenfeld (orgs). A história da educação em debate: estudos comparados, profissão docente, infância, família e igreja. Rio de Janeiro: Mauad x: FAPERJ, 2012.

SARTOR, Carla Daniel. Proteção e Assistência a Infância: Considerações sobre o $1^{\circ}$. Congresso Brasileiro de Proteção à Infância. In: RIZZINI, Irma (org.). Crianças Desvalidas, Indígenas e Negras no Brasil: cenas da Colônia, do Império e da República. Rio de Janeiro: USU Ed. Universitária, 2000, p. 143-173. SOUSA, Celita Maria Paes de. Traços de compaixão e misericórdia na história do Pará. Tese. (Doutorado em Educação: Currículo) Pontifícia Universidade Católica de São Paulo, 2010.

STREK, Danilo. Rousseau e a Educação. Autêntica: Belo Horizonte, 2004.

VENÂNCIO, Renato Pinto. Os Expostos de Catas Altas - Minas Gerais, 1775-1875. In: RIZZINI, Irene. (org.) Olhares sobre a criança no Brasil: séculos XIX e XX. Rio de Janeiro, 1997, p.127-141.

WADSWORTH, James, E. Moncorvo Filho e o problema da Infância: modelos institucionais e ideológicos da assistência à infância no Brasil. In: Revista Brasileira de História. São Paulo, vol. 19 n. 37, set 1999. Disponível em: <http://www.scielo.br/scielo.php?script=sci_arttext\&pid=S010201881999000100006. Acesso em 23/02/ 2018. 


\section{Giane Lucélia Grotti}

Docente Adjunta da Universidade Federal do Acre- Campus Rio Branco, Centro de Educação, Letras e Artes, atuando no Curso de Pedagogia, com disciplinas da área de Infância e Pedagogia; Estágio na Educação Infantil e em Classes Hospitalare.

\section{Maria Irinilda da Silva Bezerra}

Docente Adjunta da Universidade Federal do Acre/Campus Floresta, Centro de Educação e Letras, atuando no Curso de Pedagogia, com disciplinas da área de História da Educação e Ensino de História.

\section{Como citar este documento:}

DE OLIVEIRA COSTA, Giane Lucélia; DA SILVA BEZERRA, Maria Irinilda. Assistência a infância: história de uma educação moralizante e higienista. Reflexão e Ação, Santa Cruz do Sul, v. 27, n. 3, p. 24-39, out. 2019. ISSN 1982-9949. Disponível em: <https://online.unisc.br/seer/index.php/reflex/article/view/13590>. Acesso em: doi:https://doi.org/10.17058/rea.v27i3.13590. 